\title{
Understanding the Gestalt Nature of Business Models: A Business Model Review
}

\author{
Kevin Rhoads ${ }^{1}$ \\ ${ }^{1}$ Utah Valley University, Orem, USA \\ Correspondence: Kevin Rhoads, Utah Valley University, 800 West University Parkway, Orem, UT 84058, USA.
}

Received: October 8, 2015

Accepted: November 3, 2015

Online Published: November 15, 2015

doi:10.5430/jms.v6n4p34

URL: http://dx.doi.org/10.5430/jms.v6n4p34

\begin{abstract}
As business model centered research has grown significantly over the last decade, the focus has primarily been on establishing an initial understanding of the construct. Much of the existing research has focused on defining business models, yet recent research continues to highlight the lack of common understanding of the nature of business models. In this study, I examine the theoretical foundations of business models and the extent to which each contribution is found within current research through an in-depth analysis of current business model research. Four dimensions of business models are identified and found to present in business model research over $70 \%$ of the time. However, recent reviews continue to highlight the continued lack of understanding of the construct alluding to the notion that there is more to business models than the four commonly cited dimensions of structure, value creation, value capture and value networks. Employing the framework of gestalt theory, I propose an additional dimension of business models, opportunity alignment which helps explain how the four foundational dimensions work together to establish clearer understanding of the nature of business models.
\end{abstract}

Keywords: business models, gestalt theory, value

\section{Introduction}

As business model focused research continues to emerge, many questions remain that need to be addressed. The emphasis on business models in management research is a recent and growing phenomenon. Attention to business models began to appear around 1990 with the advent of the technology boom. Technology's impact on the nature and pace of business has created a new level and speed of change in industry and thus a need for firms to be able to develop the right business models in order to be able to capture the constantly changing opportunities in a given market (Teece, 2010). Business models are gaining focus as a tool for understanding and explaining patterns of business behavior. However, an understanding of the explanatory ability of business models and how they facilitate the crafting of a viable opportunity for a venture remains largely underdeveloped.

Initially business model research was often set in a technological context examining the relationships between the emerging importance of information technology and the internet on firm dynamics (Wirtz, Schilke, and Ullrich, 2010). Within the IT sector, business models were often been depicted as the framework for information inflows and outflows facilitating IT process within a firm (Timmers, 1998). The IT perspective of business models continued to develop and expanded to encompass a wider perspective of a firm's operations with a focus on a firm's relationship with external exchange partners (Amit and Zott, 2001; Magretta, 2002). In this early work, substantial attention was given to defining of business models in search of a common understanding. My extensive review of the business model literature yields more than 40 different definitions.

Although a definition is a valuable point of departure for specific research projects, a unified definition of business models does not seem to be forthcoming nor should it be expected given the track record of entrepreneurship and other fields of study in the social sciences. More importantly, definitions alone typically stop short of creating a clear picture of the boundary conditions and explanatory ability of business models. I argue that business model inquiry needs to move beyond definitional issues and focus more on boundaries, the construct, and the dimensions that make up business model. It is this level of progression that allows for a clearer understanding of the elements of business models, the relationships between those elements, and identification of the unique domain of business models through establishing distinct boundary conditions in order to understand the theoretical basis of business models (Dubin, 1969). Although current research contains many commonalities regarding the elements that contribute to a 
business model, current research stills calls for a clearer depiction of the construct and its explanatory focus (Zott, Amit, and Massa, 2011). In this light, the purpose of this paper is to examine the commonly utilized dimensions of business models through the lens of gestalt theory as a means of moving beyond definitions and toward construct clarity and understanding the broader nature of business models.

Through this analysis, several important contributions are provided. First, I examine the business model construct and the core management domains which have contributed to our current understanding of business models. This provides a theoretical basis for clarify the elements of the construct as an important initial step examining business models as a whole. Second, I conduct a thorough review of existing business model literature to understand how the contributions of existing research domains are manifest in business model focused research. In this step, the commonly identified elements of business models are articulated and validated using current research in high quality journals. This provides the basis for understanding the theoretical foundations of business models, the key elements of business models and most importantly, the nature of business models as a whole. Finally, this paper proposes an additional dimension of business models utilizing the lens of gestalt theory to help bridge the gap between understanding the individual elements of business models and understanding the distinct explanatory domain of business models.

In order to accomplish these contributions, this paper will proceed in the following manner. I begin with a review of the current state of business model understanding. This is accompanied by a review of the foundational domains of organization design, strategy, and customer marketing highlighting their contributions to business model research. Following this section, I conduct an extensive literature analysis to assess the extent of the contributions in current literature and articulate the most commonly cited elements of business models. I then employ gestalt theory to address the composite nature of the business model construct and explore the relationship between the elements when combined. Finally I conclude with a proposed path for future research.

\section{Literature Review}

\subsection{Current Business Model Research}

Business models as a focus for both practitioners and researchers is emerging as an important concept in recent years for several reasons. First and most visibly is the wide spread emergence of the internet in the late 1990's and early 2000's. Business models often appeared at this time to be a mechanism for explaining the rise and role of technology within a firm. Second, technological innovation increased at rapid rates. With innovation occurring at faster rates, new firms began to emerge with new business approaches that could allow ventures to pursue new opportunities. This phenomenon introduced a new dialogue about the relationship between innovation and business models (Hedman and Kalling, 2003). A third factor contributing to the rise of business model importance is the issue of globalization. With access to information in new ways, the ability to communicate with, transact with, and service exchange partners across multiple countries became a viable option for firms. With the emergence of the internet, the global business community was beginning to be accessible by new firms of all sizes and ages.

The ability to acquire information, an increase in the speed of business and new technology introductions, and the ability of firms to globalize were all effects of the internet and technology boom of the 1990's. These factors created changes in the global economy at an increasing pace impacting firms of all sizes and ages. These changes dealt with product innovations, emerging and new markets, regulatory adjustments, and many other aspects of industry which impacted firms in seemingly new ways (Rackham and DeVincentis, 2000). Traditional key firm characteristics such as the size of and age of a firm became less critical as businesses attempted to commercialize new products, enter new markets, and service new customers. Ultimately, these changes created the opportunity for businesses to adjust their architecture and focus in order to be able to take advantage of the new opportunities within markets, attract future investors and develop more efficient and viable ways of doing business. The internet and technological innovations previously discussed provided alternatives to existing means of conducting business. These changes in technology resulted in firms creating new business models to be able to take advantage of the emerging opportunities leading to a rapidly increasing focus on understanding the importance of business models (Hedman and Kalling, 2003).

Academic interest in the business model construct began to emerge in the 1990s. Reviews such as those completed by Timmers (1998), Morris, Schindenhutte, and Allen (2005), Schweizer (2005), Currie (2004), Hedman and Kalling (2003), Amit and Zott (2001) and others have attempted to synthesize the broad stream of emerging research primarily by defining business models and identifying elements of business models. Table 1 below outlines five of the most commonly cited definitions found in the reviews above as well as found generally within business model 
publications in top tier management journals. The definitions begin with Timmers' early work in 1998 and continue through to recent work by Teece in 2010 .

Table 1. Review of commonly cited business model definitions

\begin{tabular}{|c|c|}
\hline Author(s) and Year & Definition \\
\hline Timmers, 1998 & $\begin{array}{l}\text { The business model is "an architecture of the product, } \\
\text { service and information flows, including a description } \\
\text { of the various business actors and their roles; a } \\
\text { description of the potential benefits for the various } \\
\text { business actors; a description of the sources of } \\
\text { revenues" (p. 2). }\end{array}$ \\
\hline $\begin{array}{l}\text { Amit \& Zott, 2001; } \\
\text { Zott \& Amit, 2007, } 2008\end{array}$ & $\begin{array}{l}\text { The business model depicts "the content, structure, and } \\
\text { governance of transactions designed so as to create } \\
\text { value through the exploitation of business } \\
\text { opportunities" (2001: 511). }\end{array}$ \\
\hline $\begin{array}{l}\text { Chesbrough \& } \\
\text { Rosenbloom, } 2002\end{array}$ & $\begin{array}{l}\text { The business model is "the heuristic logic that connects } \\
\text { technical potential with the realization of economic } \\
\text { value" (p. 529). }\end{array}$ \\
\hline Magretta, 2002 & $\begin{array}{l}\text { Business models are "stories that explain how } \\
\text { enterprises work. A good business model answers } \\
\text { Peter Drucker's age old questions: Who is the } \\
\text { customer? And what does the customer value? It also } \\
\text { answers the fundamental questions every manager } \\
\text { must ask: How do we make money in this business? } \\
\text { What is the underlying economic logic that explains } \\
\text { how we can deliver value to customers at an } \\
\text { appropriate cost?" (p. 4). }\end{array}$ \\
\hline Teece, 2010 & $\begin{array}{l}\text { "A business model articulates the logic, the data and } \\
\text { other evidence that support a value proposition for the } \\
\text { customer, and a viable structure of revenues and costs } \\
\text { for the enterprise delivering that value" (p. 179). }\end{array}$ \\
\hline
\end{tabular}

These definitions have provided a basis for additional work on the subject and have been an important part of the evolution of business model research (Zott et al., 2011). Visible within these definitions are the themes of value and a firm's relationships with its exchange partners throughout its value network.

Timmers (1998) proposed a definition of business models which focused on the ability of a firm to address technological innovation and was based primarily in an IT context. Other aspects of business models center on creating a framework for how a firm makes money (Chesbrough and Rosenbloom, 2002; Morris, Schindenhutte, and Allen, 2005). Morris et al. (2005) call for additional work on understanding more clearly what makes up a business model and how a business model affects firm performance. Magretta (2002) discusses business models as stories that explain key questions regarding a firm. Zott and Amit (2007) suggested a broader perspective of business models addressing multiple stages of a venture's value chain and more broadly, the venture's value network. Specifically they identified key aspects such as value and relationships with exchange partners. Zott and colleagues continued this synthesis in a recent review concluding with a call to establish greater clarity of the construct and where exactly business models fit within the challenge of explaining firm dynamics (Zott, Amit, and Massa, 2011). The common 
conclusion for each of these reviews is that there is still a wide variance in understanding of the construct and the role of business models in explaining firm performance.

Despite the increasing number of publications focused on business models, there remains a lack of clarity about the construct itself. Some have argued that business models are a static view of a firm's organization (Baden-Fuller and Morgan, 2010); whereas others have proposed a more dynamic view discussing the role of business models in the innovation process (Gambardella and McGahan, 2010; Sosna, Trevinyo-Rodríguez, and Velamuri, 2010). Further still, recent research has proposed the need, and even attempted to summarize the various definitions and representations of business models in order to synthesize the vast body of articles into a comprehensive definition and understanding of the concept (Baden-Fuller and Morgan, 2010; Fetscherin and Knolmayer, 2004; Schweizer, 2005; Zott and Amit, 2010). This emphasis on definitions provides understanding on the commonalities that are beginning to emerge in business model research. However, critical limitations develop as well. Definitions can often lead researchers down the path of attempting to identify which definition is right among the many proposed or even in the development of new definitions. We can find evidence of this in the emergence of other domains such as entrepreneurship. Early work focused on defining what entrepreneurship is and who is an entrepreneur. As research continued to examine these questions, the push has started to move away from defining entrepreneurs and more toward identifying the boundary conditions that exist between entrepreneurship focused research and other domains. A key step in this process is a clear understanding of the foundations of the domain or construct of focus. This step has started to emerge in more recent work discussing the relationship between business models and other core management domains. Specifically, Zott, Massa, and Amit (2011), Teece, (2010), George and Bock (2011) and others have individually highlighted or alluded to contributions from three specific domains: organization design, strategy, and customer marketing.

Understanding how each of these foundational disciplines contributes to our understanding of business models not only provides a theoretical basis for the construct development, but also helps to draw boundary aiding in the identification of the distinct domain of business models. The following section will consider each of these domains and articulate the core focus and assumptions of each, how each has contributed to the development of the business model construct as well as the limitations of each in addressing business models as a whole.

\subsection{Organization Design}

Organization design is made up of several aspects that focus on the organization as a central unit of analysis. Essentially, the focus of organization design research is based on how to bring people together, coordinate their activities and relationships, and produce as much output as possible. The idea is that an organization is made up of individual actors grouped together in order to accomplish some common purpose. The more complex the task to be accomplished the more complex the organization. Large or complex tasks are broken into smaller manageable segments and actors grouped according to a specific component of the task to be accomplished. This creates the need for interdependencies and coordination between groups in order to accomplish the whole task in an efficient manner (Pfeffer, 1978). The composition of actors and groups of actors is referred to as the structure. Structures develop through on-going differentiation of various key activities.

Thompson (1967: 51) defines structure as the "patterning of relationships or activities in organizations." Karl Weick (1969) discussed the idea that structure is the relationship between roles or responsibilities within the organization. Jeffrey Pfeffer defined organization design as the process of grouping activities, roles, or positions in the organization to coordinate effectively the interdependencies that exist (Pfeffer, 1978: 25). The basis of organization design is the ability to coordinate individuals in such a way that the goals of the organization can be accomplished (Cyert and March, 1963). The core assumptions are based on people organizing to accomplish goals and is focused internal to the firm (Zott and Amit, 2007). The central focus is to bring together disparate parts, coordinate them in such a way as to control the flow of information, reduce uncertainty, and delineate lines and types of authority all in order to accomplish a common goal: an internally focused perspective (Child, 1973).

Through this overview, it is clear that there are basic concepts of organization design that are a part of the foundation of business models, namely the need to structure effectively to achieve goals. In this context, business models are depicted as the organizational structure that a firm must undertake in order to effectively transact with partners (Zott and Amit, 2008). The structure of the firm is central in the organization design perspective of business models. The nature of business models within organization design is primarily a static model of firm configuration (Amit and Zott, 2001). Business models as organizational form are important not only as means of transaction focused configuration with partners but also as a method of signaling firm legitimacy to the market and investors as new opportunities are undertaken by the firm (Sanders and Boivie, 2004). Structure is an important part of this process and contributes to 
our understanding of what comprises a business model and is often included in the various definitions provided in current research.

However organization design, and specifically structure, has a much different focus than the over concept of business models and is not alone fully able to provide an understanding of the basis of a business model. Organization design is internally focused on coordination. Although this is an element to consider within business models, it must also be noted that business models involve a broader perspective of structural issues not addressed by organization design (Amit and Zott, 2001). Business models address the structural issues of a firm from both an internal perspective as well as from an external perspective addressing the structure of the firm in the context of how best engage with potential exchange partners (Yunus, Moingeon, and Lehmann-Ortega, 2010). Thus organization design contributes one important component of the theoretical foundation of business models in the attempt to clarify the overall concept of business models.

\subsection{Strategy}

A central question for strategy research is: "What decisions should be made in order to effectively compete so firm value can be increased?" Strategy as a field of study provides important insights regarding a firm's quest to gain a sustained competitive advantage. In so doing, strategy focuses on the decisions of managers regarding firm initiatives such as innovation, top management teams, responses to industry structure, resource acquisition, and rents and value chain analysis. (Barney, 1991; Casadesus-Masanell and Ricart, 2010; Porter, 1985).

Strategy is an important contributor to current business model understanding. A central theme of business models is value (McGrath, 2010) and within the question of competitive advantage within strategy research, several key aspects such as value creation, value capture and a firm's value chain are central elements. Value creation, is emerging as a central concept of relevance in better understanding a firm's quest to gain a competitive advantage (Sirmon, Hitt, and Ireland, 2007). In this view, value creation is expressed as firm decisions on how to use resources or resource bundles in way that will yield a stronger resource set in relation to competitors. Contributing to the concept of business models, value creation within this context is focused on the ability to produce a product or service that is superior to competitors. Although an important component of business models, value creation in this context is limited to only one aspect of business models: the output. Thus an important element of business models yet limited within the strategy lens of research.

Additional contributions of strategy lie in the concept of value capture. Within strategy, the idea of value capture or rent appropriation underscores the importance of garnering economic value from efficient uses of resources by a firm (Crook et al., 2008). The importance of this concept within business models is the ability to not only create value through the business model but to have mechanisms in place to capture the value as well. For example, the search service provided by Yahoo is an important value creating service for users, but by itself does not lead to increased revenues or profits by Yahoo. There had to be developed a mechanism through which the value of search to customers could lead to economic value for Yahoo. This focus on value capture is companion to value creation in many current definitions of business models and central to the overall concept of business models (Baden-Fuller and Morgan, 2010). Although the strategic focus of rent appropriation contributes to our understanding of one aspect of business models, its profit focus is not able to address the broader picture of value capture of business models.

A third contribution of strategy to current business model understanding is the concept of the value chain. Within strategy, the value chain is a main framework for the decision making process of managers. Porter (1985) discussed four main steps associated with manager decisions making and value chains. They are (1) the ability of the managers to identify the focal business (2) the ability to identify key activities (3) determining product focus and (4) understanding which activities were most important for the firm to undertake. These four steps, known as value chain analysis, contribute in many ways to understanding the role of the value chain in business models; however the value chain is expanded beyond these steps to a broader perspective of potential external partners within the context of business models. Amit and Zott (2001) discuss this as the framework of potential exchange partners where value creation may take place within the business model context. This framework extends beyond the linear set of activities that moves from raw materials to final product output traditionally associated with a value chain. In the context of business models, this framework links previously unlinked exchange partners together creating a broader value network within which a venture must exist (Peppard and Rylander, 2006). It is within this broader perspective of a value network where a firm is able to identify potential exchange partners in the pursuit of specific opportunities regardless of the partners' affiliation or placement within a traditional value chain. The value network provides the basis to be able to develop relationships with exchange partners and create value within those relationships leading to optimal performance (Zott et al., 2011). Business models delineate the configuration of the firm and the links 
established with exchange partners across the value network to create and capture value. As evident, strategy contributes multiple facets to our current understanding and existing definitions of business models yet business models extend beyond the strategic perspectives of value creation, capture and the value chain (Magretta, 2002).

\subsection{Customer Focused Marketing}

If one explores the business model concept through the lenses of organization design and strategy, a common theme emerges which may seem at first the core focus of business models. That theme discussed by Chesbrough and Rosenbloom (2002), Teece (2010), Amit and Zott (2007) and others is the concept of value creation. Within work by these authors, the focus on customers and the ability to create value for a customer plays a major role in delineation of the business model construct. Although most management research on business models does not specifically address the overlap with customer marketing focused research, the emphasis on value creation makes the link critical and important to understand at least at a high level.

As the modern organization developed and industries emerged leading to intense competition, the need to understand customers and position a firm clearly against competitors also emerged leading in part to focus on customer based marketing. Whereas in strategy, Porter defines value as "the amount buyers are willing to pay for what a firm provides them measured by total revenue (Porter, 1985: 38)," the concept of value within the customer marketing domain centers on the ability of a firm to satisfy customer wants and needs (Fornell et al., 1996). This definition is less focused on revenue generation and more focused on customer perceptions of met expectations. The ability to achieve this concept of value from a customer's perspective is a continually evolving and growing body of research and emphasizes both the overall benefits and costs associated with products and service offered by a firm (Brodie, Whitmore, and Brush, 2009).

The quest to understand customer value is essentially the foundation of customer marketing (Anderson and Narus, 2004). It is widely accepted that for marketing focused efforts, the ability to create customer value is the basis for superior performance (Slater, 1997). However, much of the early work in this domain focused on the alignment between product features and customer desires which is only part of the value creation equation. More recent work has begun focusing on the relationship side of value creation and researchers such as Eggert, Ulaga, and Schultz (2006) have begun focusing on the elements of the supplier customer relationship and the impact the relationship has on the value creation equation. Within the marketing perspective, value creation is the overall ability to provide a product, service, and relationship that brings greater benefit than costs to the customer (Anderson and Narus, 2004).

This foundation contributes to the concept of value creation within business models as one considers the ability to align with customers as key members of the value network in order to provide benefits that exceeds costs both from a product or service perspective and a relationship perspective. This idea of relationship value permeates the broader business model discussions as indicated by several of the definitions presented earlier. Throughout the existing body of business model literature, the concept of value creation is prevalent. McGrath (2010) addresses the role of business models in bringing in the customer perspective to be able to create value. Extending this perspective however is the idea that value creation is much more than just the customer understanding and interaction (Shafer, Smith, and Linder, 2005). Value is created throughout the value network and like other foundational concepts discussed, is much broader than the traditional marketing perspectives provide. As with organization design and strategy, customer focused marketing contributes to our current understanding of business models yet by itself, it is only partially able to address the explanatory ability of business models.

\subsection{Business Model Literature Analysis}

Organization design, strategy, and customer marketing each provide elements of greater understanding when considering business models. Bringing the contributions of these three domains together to better understand the theoretical basis of the key dimensions of business models provides a greater context for creating construct clarity and understanding the holistic nature of business models. Although many authors (i.e. Amit and Zott, 2001; Teece, 2010; Morris et al., 2005; Fetscherin and Knolmayer, 2004; Schweizer, 2005) have conducted literature reviews to develop definitions of and insights into business models, there remains the need to clarify the theoretically based key elements of business models in order to understand how the relationships between the elements lead to a better understanding of business models. In order to accomplish this task, I followed the review process presented by Haleblian et al. (2009), and conducted a systematic review of a broad selection of business model research. I followed five steps in order to manage the broad range of potential articles on the subject. First, I performed a search using Business Source Premier using the word string "Business Model" in abstracts and titles (Stähler, 2001). This produced 9,388 results. Second, in order to focus the search from the broad range of topics and journals I narrowed the list down to academic journals which produced 1,349 results. From this search, the third step involved a review 
of the titles and abstracts yielding a narrowed selection of articles to 224 articles focused on business models within firms found in management, marketing, and MIS as well as to leading practitioner journals such as Harvard Business Review and Sloan Management Review. As my purpose was to focus on top tier journals, I selected those articles published in top tier academic journals focused on business models. As academic research on business models is newly emerging, there were only a small group of top tier management journals to date with articles published on the topic. The journals included the Academy of Management Executive, Academy of Management Perspectives, Strategic Management Journal, Journal of Management, Entrepreneurship Theory and Practice, Organization Science, Journal of Marketing, Journal of Management Information Systems and Long Range Planning. This selection provided 32 articles which represent the business model-centered research within the high quality management journals.

Business model analysis results: With this sample, I proceeded to review each of the 32 articles with two main objectives in mind. First was to identify convergent threads within the various definitions and second was to understand the consistency of each of the dimensions within current research. In so doing, I began coding each of the articles based on identifying the foundational elements identified previously through my review of the domains of organization design, strategy, and customer marketing. I coded each of the articles' reference to the elements of value creation, value capture, value network, and structure to determine the frequency of each element in top tier management publications as a measure of consistency of acceptance of the central dimensions of business models. If an article presented any of the four identified dimensions of a business model, I marked the dimension in the appropriate category. All of the articles had more than one category marked. Upon completion of the coding process, I added up the number of times each of the seven categories was referenced. This coding process revealed that the four dimensions or elements identified earlier were each present in more than 70 percent of the articles examined. Elements of structure were found to be present 71 percent of the time. Not surprisingly, value network which is often closely linked to structure also appeared about 71 percent of the time. Value capture appeared 84 percent of the time, and value creation appeared 90 percent of the time. These results indicate an important element of convergence of the theoretical roots of business models as well as consistency of the core dimensions of the business model construct. The question remains, with the level of consistency surrounding the core dimensions of business models, why does the persistent confusion regarding the nature and distinct domain of business models continue to exist?

Each dimension is important in building a common understanding of business models however each has limitations as well based on their roots within their foundational domains. It may seem that the business model construct is simply the aggregate of these basic dimensions and that creating a definition from these dimensions should lead to a clear understanding of business models. However upon closer examination it is clear that there is more to the business model construct than simply these four dimensions pieced together. The presence of these four dimensions provides a portion of understanding regarding business models, but as Zott et al., (2011) state, there is still a missing element to our ability to understand the broader nature of the construct. Although these four dimensions provide a degree of clarity regarding the make-up of business models, as argued by Zott et al. (2011) the continued focus on these dimensions alone may actually be partially responsible for the continued confusion regarding business models. This confusion stems from the inability of these four dimensions alone to fully explain the construct and its explanatory ability. Looking beyond the commonly identified dimensions of a business model to an understanding of the nature of the combined dimensions can help establish clearer boundary conditions as well as increase understanding regarding the distinct domain of business models.

\section{The Gestalt of Business Models}

The above analysis above indicates the presence of meaningful consistency surrounding the foundational dimensions of business models. While this is an important contribution, it still does not resolve much of the confusion surrounding the nature of business models. The lack of clarity is evidenced in both review articles on business models calling for further construct clarification (Zott et al., 2011) and the emphasis on attempts to provide new definitions of business models in order to help mitigate the lack of common understanding (George and Bock, 2011; Teece, 2010). Zott et al., in their 2011 review of business model research concluded:

"Despite the overall surge in the literature on business models, scholars do not agree on what a business model is. We observe that researchers frequently adopt idiosyncratic definitions that fit the purposes of their studies but that are difficult to reconcile with each other. As a result, cumulative progress is hampered. Current research has established the need to continue to move beyond current properties of business model definitions to be able to more clearly understand the broader nature of the construct (Zott, et al., 2011: 1020)." 
Whereas definitions are necessary at some level, particularly with early stage research as with business models, continued focus on definitional issues seem to actually limit the progression of the emergence of business model research. Focus on definitions can help to clarify the dimensions or elements of business models, yet as indicated by Zott et al., (2011) above, definitions alone are not able to clarify the broader nature of the construct and the theoretical basis of the construct as outlined by Dubin (1969). Research needs to be able to understand the theoretical foundations of a construct, work to establish a clearer set of boundary conditions through understanding the relationship between the core elements, and identify distinct explanatory opportunities. The business model construct does indeed have foundational roots in organization design, strategy, and customer marketing but business models can also seem to address elements of a firm's activities beyond the limitations of each individual dimension previously discussed (Amit and Zott, 2001; Magretta, 2002; and McGrath, 2010). It is evident that a common understanding remains an important gap leading to the continued need to be able to identify the distinct domain of business models.

The four individual contributions of structure, value creation, value capture, and the value network do not fully explain the construct. Thus, I argue that business models are more than simply the combination of the four dimensions contributed by organization design, strategy, and marketing. Drawing on the early work of Wertheimer (1938), I utilize gestalt theory to help further our understanding of the business model construct. Rather than the whole being determined by the presence of the individual elements, gestalt theory suggests that the individual elements gain meaning from being a part of the whole (Wertheimer, 1944). This is more than simply the whole being greater than the sum of the parts. It states that when individual dimensions of a construct are combined, there is an additional unique property that emerges. This new unique property is only visible when the individual dimensions are considered as a whole (Wertheimer, 1944). Ambiguity involving complex constructs can often arise from attempts to understand only the individual elements of the construct, and not how the various components fit together as individual parts to make a whole (Rindova, Ferrier, and Wiltbank, 2010).

Gestalt properties are those that rely on the relationship that exists when individual elements are combined and helping establish an understanding of the whole not able to be derived by examining the individual components alone (Kimchi, 1992). Consider the following example of Ehrenfel (1988) to help explain the concept of gestalt: If a musician plays a melody comprised of 6 tones and then plays the same melody comprised of 6 different tones, the listener would be able to identify the melody in both instances. Likewise if a musician plays the 6 original tones in a different combination, the tones stay the same but the melody is now different. There is evidently something beyond simply compiling the 6 individual tones which makes up the melody. It is this additional property of the gestalt of the melody which transforms the 6 individual tones into a recognizable melody, even when the specific tones may change. The relationship between the tones once combined creates a unique property which is the melody. The melody is clear once the individual tones are combined, but is not present alone in the tones when considered individually. This is an important element of the gestalt nature of business models as a means to help answer the call from above by Zott et al. (2011). Just as it is very difficult to identify the melody from the musical tones as individuals, focus on the individual dimensions of a business model rather than the combined whole will fail to yield the gestalt property of business models. This amplifies the challenge of current research to be able to develop understanding of the broader nature of business models.

Reconsidering the review of business model literature discussed earlier in this paper suggests the existence of the gestalt nature of business models. It is evident that the individual dimensions of structure, value creation, value capture, and the value network are recognized as key components of a business model within the current research with great consistency. However, even with the identification of the four dimensions from our review, the continued call for clarification and new understanding of business models indicates that something is still missing. As Zott et al. (2011) point out, there remains confusion as to what actually is a business model and more specifically, as to the broader nature and explanatory ability of business models. It is often impossible to understand complex constructs when focusing on each individual element of the construct due to the insights which come from understanding the elements in combination (Dubin, 1969). It is essential to understand not only the individual elements but the relationships between them. Continued confusion regarding the business model construct may be in large part due to the focus on identifying and understanding these dimensions individually and that when examined as a whole that an additional dimension or property of business models becomes visible: opportunity alignment.

Each of the four dimensions identified above is able to provide some understanding into a firm's business model. Current research examines these dimensions while attempting to articulate a depiction of the business model construct. Examples include how to organize in order to create value in unique ways, the ability to understand and create relationships with new or shifting markets, and establishing transactions with existing as well as unique 
partners (Ilinitch, D'Aveni and Lewin, 1996; Smith, Binns and Tushman, 2010). Additionally, Smith et al. (2010) specifically address how a firm navigates a complex shifting market through the correct structure and position within the value network which can lead to the ability to create and capture value to address the changes brought about within these markets due to continued innovation. Alone we can gain some understanding of the role of each dimension within the venture; however each dimension is not sufficient to illuminate the firm's business model. When examined closely each of the examples above hint at the notion that as the dimensions combine there are interactions which provide greater clarity regarding the ability effectively pursue a new opportunity.

These interactions provide the basis for better understanding the opportunity alignment (gestalt property) of business models. First, consider each dimension alone. Value creation addresses the ability to meet or exceed customer needs or demands (Eggert et al., 2006). Structure focuses on the venture's internal organization to produce an output (Thompson, 1967). Value capture centers on the ability to appropriate the rents from value created, the value chain is simply the series of activities from raw materials to consumers, and the value network is a framework of potential exchange partners (Betz, 2002; McGrath, 2010; Mutaz, Al-Debei and Avison, 2011). Each describes a focused activity or state of the venture but the whole of the venture's business model cannot be identified from them individually or even as an aggregate. When examining the four dimensions once combined with each other, understanding of the broader nature of business models increases. As four combined dimensions, value creation extends to the ability of a venture to provide benefit to all potential exchange partners across a value network and considers a more comprehensive perspective of value. The ability to organize the structure creates the mechanisms for the capture of value throughout the value network not just in the form of rents from customer, but in the form of new relationships, information and learning, and even new opportunities across a single or even multiple value chains. In the combined state, the nature of the value network evolves from a linear depiction of sequential activities to a broader array of partners previously disconnected that can be linked to contribute to both value creation and value capture associated with an opportunity.

Teece (2010) expanded on this notion as he proposed that in the context of a changing market, shifts within the market bring about the possibility to address and ultimately pursue new opportunities in unique ways. It is the role of the business model to provide the framework for a firm to be able to effectively pursue new opportunities associated with changes in the market and to be able to capture the value created through this pursuit as a result. Inherent in the framework discussed by Teece and others is the presence of the individual dimensions of business models (structure, value creation, value capture and value network) which actually when combine together lead to the ability to identify an additional dimension. This new fifth dimension is focused being able to effectively pursue new opportunities that the four individual dimensions are unable to accomplish alone (George and Bock, 2011; McGrath, 2010; Teece, 2010). Teece discusses this combination of dimensions to pursue a new opportunity as an architectural rendering. Within the architectural drawing, the individual building materials are combined together and when combined generate a new outcome which is a new building. Much like an architectural drawing, the combination of the dimensions of the business model leads to a clearer picture of the whole. As the dimensions combine, they provide understanding of an additional property of business models which focuses on being able to effectively pursue new opportunities. I propose that through the lens of gestalt theory, the interactions of value creation, structure, value network, and value capture contribute lead to a fifth dimension of business models which I label as opportunity alignment. Whereas current literature focuses primarily on the four previously identified dimensions, the continued lack of clarity regarding business models partially stems from not understanding this fifth dimension. Gestalt theory provides insight into the broader nature of business models and understanding of the five instead of four dimensions which make up business models.

Opportunity alignment incorporates several aspects of a venture's pursuit of a new opportunity due to the combined dimensions identified above. As value creation, structure, value network, and value capture are combined as part of the business model they lead to the ability to more clearly understand the breadth and more favorable path to follow when pursuing an opportunity. Understanding the value that can be created is clearer when combined with the structure of the venture and the entire value network. Value capture encompasses the value created across the entire value network and the structure considers not only internal coordination of resources but the critical links to potential partners across the value network in order to create value. These interactions provide a broader perspective of the dynamic nature of business models as well as the uniqueness of each business model. The nature of the relationship of each dimension with the others creates a unique context and thus a unique element of opportunity alignment. As one dimension changes, the alignment of the opportunity will also change creating the need for further adjustments and pivots. However if one or more of the four dimensions is not clearly defined or understood, the more favorable path of opportunity pursuit may also be more difficult to understand. 
As each dimension of a business model comes together, it is proposed that the connections between each dimension yield the additional dimension of opportunity alignment. The venture's structure connects to the value network to more clearly articulate the venture's links with exchange each partner. Adding in the role of value creation, creates greater understanding into what value can be created and how the venture should link with identified exchange partners to effectively pursue a new opportunity. Additionally, the dimension of value capture provides greater insight into the specific nature of the links between the venture and its exchange partners and how each link contributes to the venture's ability to pursue the new opportunity in a viable manner. It is in this combined perspective that the fifth dimension of opportunity alignment becomes more clearly visible. As a stand-alone term, alignment means the ability to coordinate or connect parts in relation to a common goal. In this context, opportunity alignment can thus be defined as the connection or coordination of structure, value creation, value capture, and value networks in order to effectively engage in the entrepreneurial enactment process.

Evident in this description of opportunity alignment is the dynamic nature of the dimension. This dynamic component of opportunity alignment provides greater clarity in the existing debate of whether or not business models are a static framework or a dynamic process. Business models when considered through the lens of gestalt theory provide a link to addressing both perspectives. There is a static model based element of business models which is most commonly explained through understanding the dimensions of structure, value creation, value capture, and value network. These provide insight into the framework of the business model, or the architectural aspect of business models (Teece, 2010). Additionally when the gestalt property of business models, opportunity alignment, is considered, a dynamic element is introduced. This dynamic element of business models addresses both an external and an internal perspective. Opportunity alignment, in part, addresses the ability of a business model to adjust or pivot based on changes in the market as discussed by George and Bock (2011). At this level, this is similar to the description of dynamic capabilities as posited by Eisenhardt and Martin (2000). Teece (2007) discusses the role of dynamic capabilities as a resource that a firm uses to implement its business model in the face of changing opportunities or market conditions, again pointing to the dynamic nature of opportunity alignment with an external focus.

However, opportunity alignment goes beyond the traditional definitions of dynamic capabilities as it addresses the internal coordination between key elements of new venture. In this case, the dynamism of opportunity alignment is more specifically focused on internal coordination even in the pursuit of a stable or non-changing opportunity. It is clearly possible that an opportunity has been found and is relatively stable in the market and the dimension of opportunity alignment is the dynamic process of internal coordination to be best able to pursue the opportunity. Where opportunity alignment can be a type of dynamic capability it extends beyond dynamic capabilities.

This is best seen when considering real world scenarios of entrepreneurs pursuing new opportunities. Consider a team of entrepreneurs who were attempting to commercialize a new bio-fuel focused on generating fuel for heat. As they developed the technology and considered the possible markets and opportunities, they began presenting their plan to others in attempts to begin the commercialization process. In discussing their concept and business model with industry experts, potential customers and potential investors, they received feedback that their initially target home heating market was going to be problematic because of distribution and seasonality challenges. Consequently, they reconsidered their business model and ended up readjusting their distribution and customer market indicating the dynamic nature of business models. In this case the dynamism was more about gaining critical understanding and coordinating a new venture to be able to pursue a relative stable opportunity incorporating both an external focus and an internal focus.

Such realignments are actually a common occurrence with entrepreneurial endeavors and can be easily understood when considering the gestalt nature of business models. If there is a gap in understanding of any of the four foundational dimensions of a venture's business model, the gestalt property of opportunity alignment will reflect the same gap in the business model framework. Additionally, opportunity alignment can actually help expose potential flaws in a new venture's plan and provide a clearer path for how to address potential opportunities. If the potential for value creation is not understood across the entire value network and a venture only focuses on the customers, the gestalt property will also only take into account alignment from the customer's perspective and miss the potential for value creation and alignment with a broader set of exchange partners within the value network. This example is depicted in the differences between Google and other early search engines. Value creation and value capture were not clearly defined across the entire value network by Google's early competitors which caused very different perspectives of effective opportunity alignment between each company. Each venture's business model contained elements of value creation, structure, value capture (although in varying degrees), and value network, yielding a framework for opportunity alignment which yielded very different paths for opportunity pursuit and thus contributed 
to the differences in outcome and Google's comparative success. Early competitors' business models incorporated the dimensions of value creation capture from a per user perspective and introduced banner ads as a result. Google articulated value creation and value capture in a much broader sense. For example, they incorporated a unique group of exchange partners leading to a quicker search process, a more focused advertising strategy, and a clearer understanding of how their structure should connect with the value network in order to facilitate the value creation and capture process. This is evidenced in their recent relationships established with partners such as NASA, News Corp, NORAD, and even the Pontifical Council for Social Communications (Krause, 2009; Lewis, 2005). This clearer perspective of each of the four dimensions combined to provide a direct path for effective pursuit of the opportunities at hand, or in other words created an additional dimension of opportunity alignment which help to contribute to Google not only being the dominant firm in their industry, but in the word Google becoming an official part of common vocabulary meaning to search (Harris, 2006).

It is through understanding the combined nature of the four core dimensions of business models and the alignment that exists within the combined dimensions that research can begin to address the lack of progress cited by Zott et al., (2011) and create a clearer understanding of the broader nature and unique explanatory ability of business models.

\section{Discussion and Future Directions}

The rise in business model research over the past 15 years has led researchers to focus on attempts to understand what business models are plus how they may provide understanding and insight to management research. Business models are important factors in firm performance (Zott and Amit, 2008), yet a clear understanding of what business models are and how they work is missing. This paper explores the underlying theoretical foundations of business models as contributed by core domains such as organizational design, strategy, and customer marketing plus identifies the specific dimensions of each. Further, this paper examines the prevalence of these contributions in current business model research published in high quality management journals. Finally, to address the continued lack of clarity around business models despite the growing body of research focused on setting forth definitions and identifying several common dimensions of the construct, I apply gestalt theory to the business model context. Gestalt theory examines the holistic nature of a complex construct such as business models stating that business models are more than the result of combining together their identified individual dimensions. It is through understanding the relationship that exists between these dimensions when combined that yields a more complete understanding of the broader nature business models and thus the unique explanatory ability of the construct. Current research has primarily focused on the definition and dimensions of business models stopping short of considering the relationship between the dimensions when combined or the gestalt nature of business models: opportunity alignment. Business models as gestalt aides our ability to understand the distinct domain of business models: the pursuit of opportunities which in other words provides insight into the theory of each individual firm. The gestalt property of business models, opportunity alignment, emerges more clearly when the individual dimensions of business models are examined as a combined model. As each dimension is considered in conjunction with each of the other dimensions the relationships between them provide insight into how a venture should best address potential opportunities. As one dimension changes, the approach to pursuing the opportunity also changes to ensure that each dimension is properly developed.

This new dimension of opportunity alignment has important implications on several aspects of Entrepreneurship research. First of all is the clearer understanding of the theoretical foundations of business models and their role within entrepreneurship. Traditional research has continued to ask the questions of what is a business model and of whether or not business models are distinct or simply a part of organization design, strategy, or even customer marketing. An examination of these domains clearly identifies key aspects of business models which each domain has contributed. These aspects or dimensions are identified as structure, value creation, value capture, and the value network. These dimensions are important elements of business models and contribute to our understanding of the construct as they provide insight into the architectural framework of a business model (Teece, 2010). These four foundational dimensions are important and are found to be highly consistent in recent research focused on business models. Yet despite the commonality of these four dimensions of business models with the research, there remains a high level of ambiguity regarding understanding what a business model is and how it works.

Additionally, this paper moves beyond definitions and explores not only the four dimensions themselves, but the relationships between those dimensions. It is this process that pushes the field forward in beginning to draw boundary conditions and establish the theoretical viability of business models as a research domain (Dubin, 1969). Through this process, business models are found to indeed be different from core domains such as those listed above. Each of the existing domains contributes to our understanding but each is limited in its ability to address the 
construct as a whole. Structure, value creation, value capture, and value network provide understanding into the key aspects of a new venture. However when examined individually they do not fully address the questions surrounding business models. This is evidenced in the myriad of articles continuing to address the nature and definition of business models. Each proposes some combination of several or even all of the four dimensions identified in this paper yet each continues to imply there is more to business models. When taken together the dimensions of business models create a clearer picture of how a firm addresses opportunities through understanding the theory of an individual firm. This helps to continue to delineate the focus of business models in addressing new opportunity pursuit. It is the combined nature of the four foundational dimensions leading to the fifth dimension of opportunity alignment which provides additional understanding into the boundary conditions of the construct. Understanding the nature and role of opportunity alignment focuses the business model construct on the ability to better explain how new ventures address new opportunities.

Another impact is the clarification of potential future research streams focused on business models. Initially is the importance of being able to validate the presence of each dimension of business models within new ventures through focus on not only the four dimensions outlined, but on the broader nature of the construct as depicted through the lens of gestalt theory. As discussed earlier, one way to do this is to isolate the context to new ventures and understand the role of each of the four dimensions within a new venture as well as the nature of the four dimensions when combined. Following the lead of Gartner (2007) and others, the narrative or interview process may provide the framework for this process. The ability to interview entrepreneurs and have them outline the dimensions of the business models as well as articulate the story of their business may allow for the ability to address the impact of combining the dimensions listed above to engage in the entrepreneurial enactment process (George and Bock, 2011). This will aid in developing construct clarity and in continuing to establish divergent validity. Additionally, it is important to further understand the links between business models and venture growth. Do business model choices impact venture progression? Can business model choices amplify resource strengths and weaknesses or even compensate for a lack of certain types of resources? Finally a potential path for future research is through examining the antecedents of business models. What factors impact the choice of business models and how do business models account for potential weaknesses within new ventures?

This paper puts forth several contributions of note. First of all is a review of the core domains of organization design, strategy, and customer focused marketing in order to provide a clearer picture of the theoretically based contributions of each to our current understanding business models. This review resulted in four clearly articulated dimensions of business models, structure, value creation, value capture and the value network. Additionally this process outlined the contributions as well as the limitations of each of the domain in addressing the business model construct which aides in creating clearer boundary conditions and distinctions between business models and the domains of organization design, strategy, and customer marketing.

This leads to the second contribution of this paper. This article presents a thorough review of current business model research published in high quality management journals to understand how the dimensions mentioned above manifest themselves in business model publications. A high level of consistency was found between the contributions of the management domains reviewed and the inclusion of those contributions in the form of dimensions of business models. This indicates that despite the lack of clarity surrounding business models that there are several commonly accepted aspects of the construct. This is important we attempt to move the field of business model research forward.

An additional contribution is the application of the lens of gestalt theory to business models. There is a high level consistency pertaining to key aspects of business models in current research however common understanding is lacking. Through this paper I propose that one main reason is the focus on the definition of a business model and each individual dimension of business models. Gestalt theory addresses the need to examine not only the individual dimensions of business models, but the relationships that exist between the dimensions when combined which lead to a broader perspective. The whole is more than the sum of the individual parts. This perspective helps to establish a more holistic view of business models and takes into account the importance of each dimension as well as the limitation of any individual dimension in explaining the composite construct. The result of this application of gestalt theory is the delineation of the distinct focus of business models and thus a broader understanding of the construct. Business models are more than simply a venture's structure, ability to create and capture value and position and relationships within the value network. A business model in this perspective actually becomes the theory of each individual venture or firm. The role of opportunity alignment as the fifth dimension of business models allows each unique venture to address an opportunity creating clarity around the how the venture will be structured, what value the venture brings to market and how they will capture that value as well as a picture of the potential value network 
the venture will employ to address the opportunity. The role of alignment is to create the right coordination between these four aspects to uniquely allow the venture to pursue the focal opportunity. As each venture is unique and the way each venture approaches the pursuit of a new opportunity is unique, business models become the unique story of each venture.

\section{Conclusion}

Even as the use of the term business model continues to appear with more and more frequency, the understanding of what a business model is and what a business model actually does seems to vary widely. It is becoming widely accepted that the concept of business models are an important to practitioners as well as a potentially interesting research focus. However there is a lack of clarity regarding the not only the nature of business models but the distinctness of the construct. With this in mind, this paper set out to address this issue through an examination of the theoretical foundations of business models, a thorough review of current research on business models, as well as an examination of the gestalt properties of business models providing greater clarity around the nature of business models and how they work within new ventures.

\section{References}

Amit, R., \& Zott, C. (2001). Value creation in e-business. Strategic Management Journal, 22, 493-520. http://dx.doi.org/10.1002/smj.187

Anderson, J.C., \& Narus, J.A. (1999). Business Market Management: Understanding, Creating, and Delivering Value. Prentice Hall, Upper Saddle River, NJ. http://dx.doi.org/10.1108/08858629910272265

Baden-Fuller, C., \& Morgan, M. S. (2010). Business models as models. Long Range Planning, 43, 156-171. http://dx.doi.org/10.1016/j.lrp.2010.02.005

Barney, J.B. (1991). Firm resources and sustained competitive advantage. Journal of Management, 17(1), 99-120. http://dx.doi.org/10.1177/014920639101700108

Betz F. 2002. Strategic business models. Engineering Management Journal, 14(1), 21-7. http://dx.doi.org/10.1080/10429247.2002.11415145

Bonaccorsi, A., Giannangeli, S., \& Rossi, C. (2006). Entry strategies under competing standards: Hybrid business models in the open source software industry. Management Science, 52, 1085-1098. http://dx.doi.org/10.1287/mnsc. 1060.0547

Capelli, P. (2009). The future of the US business model and the rise of competitors. Academy of Management Perspectives, 23(2), 5-10. http://dx.doi.org/10.5465/AMP.2009.39985536

Casadesus-Masanell, R., \& Ricart, J. E. (2010). From strategy to business models and to tactics. Long Range Planning, 43, 195-215. http://dx.doi.org/10.1016/j.lrp.2010.01.004

Chesbrough, H. W., \& Rosenbloom, R. S. (2002). The role of the business model in capturing value from innovation: Evidence from Xerox Corporation's technology spinoff companies. Industrial and Corporate Change, 11, 533-534. http://dx.doi.org/10.1093/icc/11.3.529

Child, J. (1973). Organization: A choice for man. In John Child (Ed.), Man and Organization. London, Halstead Press.

Clemons, E. K. (2009). Business models for monetizing internet applications and web sites: Experience, theory and predictions. Journal of Management Information Systems, $2, \quad 15-41$. http://dx.doi.org/10.2753/MIS0742-1222260202

Coviello, N.E., \& Brodie, R.J. (1998). From transaction to relationship marketing: An investigation of managerial perceptions and practices. Journal of Strategic Marketing, 6(3), 171-186. http://dx.doi.org/10.1080/096525498346603

Currie, W.L. (2004). Value creation from the application service provider e-business model: The experience of four firms. Journal of Enterprise Information Management, 17(2), 117-130. http://dx.doi.org/10.1108/17410390410518763

Cyert, R.M., \& March, J.G. (1963). A Behavioral Theory of the Firm. Englewood Cliffs, NJ. Prentice Hall.

Dahan, N.M., Doh, J.P., Oetzel, J., \& Yaziji, M. (2010). Corporate-NGO collaboration: Co creating new business models for developing markets. Long Range Planning, 43, 326-342. http://dx.doi.org/10.1016/j.lrp.2009.11.003 
Demil, B., \& Lecocq, X. (2010). Business model evolution: In search of dynamic consistency. Long Range Planning, 43, 227-246. http://dx.doi.org/10.1016/j.lrp.2010.02.004

Dubin, R. (1969). Theory building: A practical guide to the construction and testing of theoretical models. New York: Free Press.

Eggert, A., Ulaga, W., \& Schultz, F. (2006). Value creation in the relationship lifecycle: A quasi-longitudinal analysis. Industrial Marketing Management, 35(1), 20-27. http://dx.doi.org/10.1016/j.indmarman.2005.07.003

Ehrenfels, C. von. (1988). On 'gestalt qualities'. In B. Smith (Ed.), Foundations of gestalt theory (pp. 82-117). Munich, Germany: Philosophia Verlag. (Original work published 1890)

Eisenhardt, K.M., \& Martin, J. (2000). Dynamic capabilities: What are they? Strategic Management Journal, 21, 1105-1121. http://dx.doi.org/10.1002/1097-0266(200010/11)21:10/11<1105::AID-SMJ133>3.0.CO;2-E

Fetscherin, M., \& Knolmayer, G. (2004). Business models for content delivery: an empirical analysis of the newspaper and magazine industry. The International Journal on Media Management, 6(1-2), 4-11. http://dx.doi.org/10.1080/14241277.2004.9669377

Fiet, J.O., \& Patel, P.C. (2008). Forgiving business models for new ventures. Entrepreneurship Theory \& Practice, 32(4), 749-761. http://dx.doi.org/10.1111/j.1540-6520.2008.00252.x

Fornell, C., Johnson, M.D., Anderson, E.W., Jaesung, C., \& Bryant, B.E. (1996). The American Customer Satisfaction Index: Nature, Purpose, and Findings. Journal of Marketing, 60, 7-18. http://dx.doi.org/10.2307/1251898

Gambardella, A., \& McGahan, A. M. (2010). Business model innovation: General purpose technologies and their implications for industry structure. Long Range Planning, 43, 262-271. http://dx.doi.org/10.1016/j.lrp.2009.07.009

Gartner, W. (2007). Entrepreneurial Narrative and a Science of the Imagination. Journal of Business Venturing, 22(5), 613-627. http://dx.doi.org/10.1016/j.jbusvent.2006.10.003

George, G. \& Bock. A.J. (2010). The business model in practice and its implications for entrepreneurship research. Entrepreneurship Theory and Practice, 35(1), 83-111. http://dx.doi.org/10.1111/j.1540-6520.2010.00424.x

Haleblian, J., Devers, C. E., McNamara, G., Carpenter, M. A., \& Davison, R. B. (2009). Taking stock of what we know about mergers and acquisitions: A review and research agenda. Journal of Management, 35, 469-502. http://dx.doi.org/10.1177/0149206308330554

Harris, S.D. (2006). Dictionary adds verb: to google. San Jose Mercury News.

Hedman, J., \& Kalling, T. (2003). The business model concept: Theoretical underpinnings and empirical illustrations. European Journal of Information Systems, 12, 49-59. http://dx.doi.org/10.1057/palgrave.ejis.3000446

Ilinitch, A.Y., D'Aveni, R.A., \& Lewin, A.Y. (1996). New organizational forms and strategies for managing in hyper-competitive markets. Organization Science, 7, 211-221. http://dx.doi.org/10.1287/orsc.7.3.211

Kimchi, R. (1992). Primacy of wholistic processing and the global/local paradigm: a critical review. Psychological Bulletin, 112, 24-38. http://dx.doi.org/10.1037/0033-2909.112.1.24

Krause, F. (2009). Pope Benedict Debuts on YouTube to Reach Out to Catholics. Bloomberg.com.

Lewis, L. (2005). NASA Takes Google on Journey into Space. National Aeronautics and Space Administration.

Magretta, J. (2002, May). Why business models matter. Harvard Business Review, 3-11.

Markides, C., \& Charitou, C. D. (2004). Competing with dual business models: A contingency approach. Academy of Management Executive, 18, 22-36. http://dx.doi.org/10.5465/AME.2004.14776164

McGrath, R. G. (2010). Business models: A discovery driven approach. Long Range Planning, 43, 247-261. http://dx.doi.org/10.1016/j.lrp.2009.07.005

Morris, M., Schindehutte, M., \& Allen, J. (2005). The entrepreneur's business model: Toward a unified perspective. Journal of Business Research, 58(6), 726-735. http://dx.doi.org/10.1016/j.jbusres.2003.11.001

Mullins, J., \& Komisar, R. (2010). Getting to plan B: Breaking through to a better business model. Academy of Management Perspectives, 93-96. 
Mutaz M. Al-Debei, \& David Avison. (2011). Business Model Requirements and Challenges in the Mobile Telecommunication Sector. Journal of Organizational Transformation and Social Change, 8(2), 215-235. http://dx.doi.org/10.1386/jots.8.2.215_1

Obloj, T., Obloj, K., \& Pratt, M.G. (2010). Dominant logic and entrepreneurial firms' performance in a transition $\begin{array}{lllll}\text { economy. Entrepreneurship } \quad \text { Theory } \& \quad \text { Practice, } & 34(1), & \text { 151-170. }\end{array}$ http://dx.doi.org/10.1111/j.1540-6520.2009.00367.x

Pauwels, K., \& Weiss, A. (2008). Moving from free to fee: How online firms market to change their business model successfully. Journal of Marketing, 72, 14-31. http://dx.doi.org/10.1509/jmkg.72.3.14

Peppard, J., \& Rylander, A. (2006). From value chain to value network: Insights for mobile operators. European Management Journal, 24(2-3), 128-141. http://dx.doi.org/10.1016/j.emj.2006.03.003

Pfeffer, J. (1978). The micropolitics of organizations. In Marshall W. Meyer (Ed.), Environments and Organizations (pp. 29-50). San Francisco: Jossey-Bass.

Porter, M.E. (1985). Competitive advantage: Creating and sustaining superior performance. New York: Free Press.

Rackham, N., \& DeVincentis, J. (1999). Rethinking the Sales Force. New York: McGraw-Hill.

Rindova, V., Ferrier, W.J., \& Wiltbank, R. (2010). Value from gestalt: How sequences of competitive actions create advantage for firms in nascent markets. Strategic Management Journal, 31(13), 1474-1497. http://dx.doi.org/10.1002/smj.892

Sabaier, V., Mangematin, V., \& Roussell, T. (2010). From recipe to dinner: Business model portfolios in the European biopharmaceutical industry. Long Range Planning, 43(2), 431-447. http://dx.doi.org/10.1016/j.lrp.2010.02.001

Sanders, W.G., \& Boivie, S. (2004). Sorting things out: Valuation of new firms in uncertain markets. Strategic Management Journal, 25(2), 167-186. http://dx.doi.org/10.1002/smj.370

Schweizer, L. (2005). Concept and evolution of business models. Journal of General Management, 31(2), 37-56.

Seelos, C., \& Mair, J. (2007). Profitable business models and market creation in the context of deep poverty: A strategic view. Academy of Management Perspectives, 21, 49-63. http://dx.doi.org/10.5465/AMP.2007.27895339

Shafer, S. M., Smith, H. J., \& Linder, J. (2005). The power of business models. Business Horizons, 48, 199-207. http://dx.doi.org/10.1016/j.bushor.2004.10.014

Slater, S.F. (1997). Developing a Customer Value-Based Theory of the Firm. Journal of the Academy of Marketing Science, 25, 162-167. http://dx.doi.org/10.1007/BF02894352

Smith, W. K., Binns, A., \& Tushman, M. L. (2010). Complex business models: Managing strategic paradoxes simultaneously. Long Range Planning, 43, 448-461. http://dx.doi.org/10.1016/j.lrp.2009.12.003

Sosna, M., Trevinyo-Rodríguez, R. N., \& Velamuri, S. R. (2010). Business models innovation through trial-and-error learning: The Naturhouse case. Long Range Planning, 43, 383-407. http://dx.doi.org/10.1016/j.lrp.2010.02.003

Stähler, P. (2002). Business Models as an Unit of Analysis for Strategizing. Proceedings of the 1st International Workshop on Business Models.

Svejenova, S., Planellas, M., \& Vives, L. (2010). An individual business model in the making: A chef's quest for creative freedom. Long Range Planning, 43(2), 408-430. http://dx.doi.org/10.1016/j.lrp.2010.02.002

Teece, D.J. (2010). Business models, business strategy and innovation. Long Range Planning, 43, 172-194. http://dx.doi.org/10.1016/j.lrp.2009.07.003

Thompson, J.D. (1967). Organizations in Action. New York, McGraw Hill.

Thompson, J. D., \& MacMillan, I. C. (2010). Business models: Creating new markets and societal wealth. Long Range Planning, 43(2), 291-307. http://dx.doi.org/10.1016/j.lrp.2009.11.002

Timmers, P. (1998). Business models for electronic markets. Electronic Markets, 8, 3-8. http://dx.doi.org/10.1080/10196789800000016

Weick, K.E. (1969). The Social Psychology of Organizing. Reading, Mass. Addison-Wesley. 
Wertheimer, M. (1938). Laws of organization in perceptual forms. In Ellis, W. (Ed. \& Trans.), A source book of Gestalt psychology (pp. 71-88). London: Routledge \& Kegan Paul. (Original work published 1923). http://dx.doi.org/10.1037/11496-005

Wertheimer, M. (1944). Gestalt theory. Social Research, 11, 78-99.

Williamson, P.J. (2010). Cost innovation: Preparing for a 'Value-for-Money' revolution. Long Range Planning, 43(2), 343-353. http://dx.doi.org/10.1016/j.lrp.2009.07.008

Wirtz, B.W., Schilke, O., \& Ulrich, S. (2010). Strategic Development of Business Models. Long Range Planning, 43(2), 272-290. http://dx.doi.org/10.1016/j.lrp.2010.01.005

Yunus, M., Moingeon, B., \& Lehmann-Ortega, L. (2010). Building social business models: Lessons from the Grameen experience. Long Range Planning, 43(2-3), 308-325. http://dx.doi.org/10.1016/j.lrp.2009.12.005

Zott, C., \& Amit, R. (2007). Business model design and the performance of entrepreneurial firms. Organization Science, 18(2), 181-199. http://dx.doi.org/10.1287/orsc.1060.0232

Zott, C., \& Amit, R. (2008). The fit between product market strategy and business model: Implications for firm performance. Strategic Management Journal, 19, 1-26. http://dx.doi.org/10.1002/smj.642

Zott, C., \& Amit, R. (2010). Business model design: an activity system perspective. Long Range Planning, 43(2), 216-226. http://dx.doi.org/10.1016/j.lrp.2009.07.004

Zott, C, Amit, R., \& Masa, L. (2011). The business model: Theoretical roots, recent developments and future research. Journal of Management Studies, 37(4), 1019-1042. 